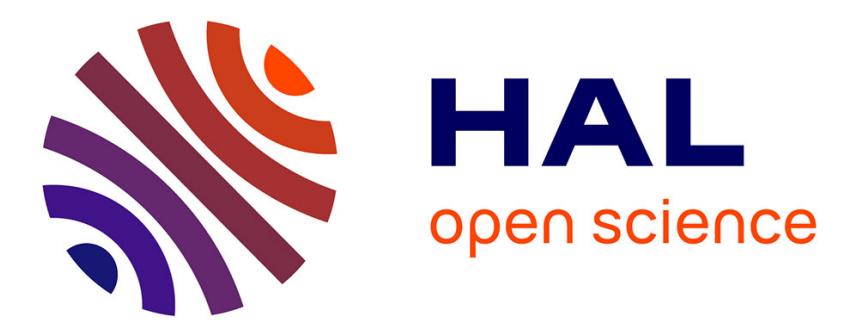

\title{
Evaluation of two therapeutic patient education programs for prevention of diabetic foot ulcers
}

Claire Marchand, Aurore Margat, Carole Deccache, Georges Ha Van, Jocelyne M’bemba, Sophie Schuldiner, Jacques Martini, Claire Parer, Rémi Gagnayre, Pierre Lombrail, et al.

\section{To cite this version:}

Claire Marchand, Aurore Margat, Carole Deccache, Georges Ha Van, Jocelyne M'bemba, et al.. Evaluation of two therapeutic patient education programs for prevention of diabetic foot ulcers. Éducation thérapeutique du patient / Therapeutic patient education , 2018, 10 (1), pp.10201. 10.1051/tpe/2018004 . hal-01924761

\section{HAL Id: hal-01924761 \\ https://sorbonne-paris-nord.hal.science/hal-01924761}

Submitted on 16 Nov 2018

HAL is a multi-disciplinary open access archive for the deposit and dissemination of scientific research documents, whether they are published or not. The documents may come from teaching and research institutions in France or abroad, or from public or private research centers.
L'archive ouverte pluridisciplinaire HAL, est destinée au dépôt et à la diffusion de documents scientifiques de niveau recherche, publiés ou non, émanant des établissements d'enseignement et de recherche français ou étrangers, des laboratoires publics ou privés. 


\title{
Evaluation of two therapeutic patient education programs for prevention of diabetic foot ulcers
}

\author{
Claire Marchand ${ }^{1, *}$, Aurore Margat ${ }^{1}$, Carole Deccache ${ }^{1}$, Georges Ha Van ${ }^{2}$, Jocelyne M'Bemba ${ }^{3}$, \\ Sophie Schuldiner ${ }^{4}$, Jacques Martini ${ }^{5}$, Claire Parer ${ }^{4}$, Rémi Gagnayre ${ }^{1}$, Pierre Lombrail ${ }^{1}$, \\ Jean François d'Ivernois ${ }^{1}$ and Agnès Hartemann $6,7,8$ \\ ${ }^{1}$ Laboratoire Éducations et Pratiques de Santé, EA 3412, Université Paris 13 Sorbonne Paris, Bobigny, France \\ ${ }^{2}$ Unité du pied diabétique, CHU Pitié Salétrière, Paris, France \\ 3 Service de diabétologie, Hôpital Cochin, Paris, France \\ ${ }^{4}$ Maladies métaboliques et endocriniennes, CHU le Grau du Roi-Nîmes, le Grau du Roi, France \\ 5 Service de diabétologie, CHU de Toulouse, Toulouse, France \\ ${ }^{6}$ Service de diabétologie, Assistance Publique-Hôpitaux de Paris (AP-HP), CHU Pitié-Salpêtrière, Paris, France \\ ${ }^{7}$ Institut de Cardiométabolisme et Nutrition, Paris, France \\ ${ }^{8}$ Université Pierre et Marie Curie, Paris 6, Paris, France
}

Received: 1 December 2017 / Accepted: 11 April 2018

\begin{abstract}
Objectives: The purpose of this study is to evaluate and compare the effects of two education programs on patients' understanding of the disease, self-efficacy, locus of control, and application of prevention behaviors for foot ulcer. Methods: In four centers that manage patients with diabetes and grade 2 or 3 neuropathy, the first arm of patients $(\mathrm{G} 1=53)$ participated in a "standard" program usually managed in each center, and those in the second arm $(\mathrm{G} 2=56)$ in a "new" program. The patients completed four questionnaires at inclusion (T0) and six months after the education (T1). Occurrence of a new foot ulcer and care behaviors were collected at T1. Z-test was used to compare mean scores for each questionnaire and Fisher's exact test for percentages $(p=0.05)$. Results: There was no significant difference between groups G1 and G2 in terms of scores for each questionnaire at T0 and T1. Group G2 showed a significant change in score between $\mathrm{T} 0$ and $\mathrm{T} 1$ for understanding the disease $(p=0.04)$ and prevention behaviors $(p=0.01)$. For the sample as a whole $(n=109)$, there was a significant improvement between T0 and T1 for two questionnaires: understanding of disease $(p<0.01)$ and declared prevention behaviors $(p<0.01)$. Patients who reported having relative to participate in care had a significantly higher mean score on prevention behaviors $(p<0.01)$. Twenty patients had developed one new ulcer since the education $(20.2 \%)$. Conclusion: This study reinforces the importance of devoting time during education to patients' understanding of the disease and involving relatives to improve foot ulcer prevention behaviors.
\end{abstract}

Key words: prevention behaviour / foot ulcer / understanding disease / self-efficacy

Résumé - Évaluation de deux programmes d'éducation thérapeutique du patient sur la prévention des plaies de pieds diabétiques à risques. Objectif : Le but de cette étude est d'évaluer et de comparer les effets de deux programmes d'éducation sur la compréhension de la maladie par les patients, l'auto efficacité, le locus de contrôle et l'application des comportements de prévention de l'ulcère du pied. Méthode : Dans quatre centres de référence pour les patients atteints de diabète avec une neuropathie de grade 2 ou 3 , le premier groupe de patients $(\mathrm{G} 1=53)$ a participé à un programme "standard" habituellement utilisé dans chaque centre, et ceux du deuxième groupe $(\mathrm{G} 2=56)$ à un "nouveau" programme. Les patients ont rempli quatre questionnaires à l'inclusion (T0) et six mois après l'éducation (T1). L'apparition d'un nouvel ulcère du pied et d'autres comportements de prévention ont été notés à $\mathrm{T} 1$. Le test $\mathrm{Z}$ a été utilisé pour comparer les résultats moyens de chaque questionnaire et le test exact de Fisher pour les pourcentages $(p=0,05)$. Résultats : Il n'y avait pas de différence significative entre les groupes G1 et G2 concernant les résultats de chaque questionnaire à $\mathrm{T} 0$ et $\mathrm{T} 1$. Le groupe $\mathrm{G} 2$ a montré un changement significatif dans le score entre $\mathrm{T} 0$ et

\footnotetext{
*Corresponding author: claire.marchand@univ-paris13.fr
} 
T1 pour la compréhension de la maladie $(p=0,04)$ et les comportements de prévention $(p=0,01)$. Pour l'ensemble de l'échantillon $(n=109)$, il y a eu une amélioration significative entre T0 et T1 pour deux questionnaires: compréhension de la maladie $(p<0,01)$ et des comportements de prévention déclarés $(p<0,01)$. Les patients qui ont déclaré avoir un proche participant aux soins ont obtenu un score moyen significativement plus élevé pour les comportements de prévention $(p<0,01)$. Vingt patients avaient développé un nouvel ulcère depuis l'éducation (20,2\%). Conclusion : Cette étude souligne l'importance de consacrer du temps à la compréhension de la maladie par les patients et d'impliquer les proches dans l'amélioration des comportements de prévention des ulcères du pied.

Mots clés : comportement de prévention / ulcère pied / compréhension maladie / auto efficacité

\section{Introduction}

Foot ulcers in at-risk diabetic patients are a true public health problem, with a prevalence of $5 \%$ in France [1]. According to the International Diabetes Federation in 2015, an estimated 9.1 to 26.1 million patients with diabetes develop a foot ulcer every year [2]. The incidence of amputations due to foot ulcers is an estimated 2 per 1000 per year, and the rate of ulcer recurrence was 30 to $40 \%$ after one year and as high as $70 \%$ after five years $[2,3]$. Four times out of five, the ulcer has an external, and thus avoidable, cause. As a result, therapeutic patient education (TPE) aimed at preventing diabetic foot ulcers has an important place among the recommendations for managing such patients [4-6]. Despite better management of these patients (including specific TPE programs on foot ulcer prevention), some patients suffer recurring foot ulcers and others do not. One study, done in 2010-11, showed that there can be psycho-cognitive obstacles to foot ulcer prevention behavior among at-risk diabetic patients [7]. We attempted to improve upon the standard education programs by placing more emphasis on understanding the disease, self-efficacy, and locus of control, while at the same time tackling the skills necessary for prevention behaviors [8-12].

The aim of this study was to evaluate and compare the effects of two TPE programs on patients' understanding of the disease, self-efficacy, locus of control, and application of foot ulcer prevention skills.

\section{Method}

We conducted a multicentric feasibility study. The study received approval from the Patient Protection Committee at one of the centers on September 3, 2013.

Four centers that manage diabetic patients at risk for foot ulcers participated in the study. They followed the international recommendations for managing grades 2 and 3 diabetes patients [5]. Management was multidisciplinary, including medical care, podiatric care (four visits for grade 2 patients and six visits for grade 3 patients), therapeutic footwear and plantar orthotics, and participation in TPE sessions on foot ulcer prevention.

All of the enrolled patients had type 1, type 2, or another type of diabetes, and had grade 2 or 3 foot risk. They had been free of foot ulcers for at least one month and needed education on the foot ulcer prevention. The patients were given information about the study and signed a consent form.

Patients were enrolled in chronological order at each of the centers; those in the first arm (group G1) participated in the "standard" program and those in the second arm (group G2) in the "new" program. The exclusion criteria were dementia, another serious disease that was life-threatening in the short term, lack of French language mastery, vision problems that made it impossible to fill out questionnaires, or an inability to perform foot care without help.

\subsection{Description of the intervention}

Two different TPE programs (standard and new) based on international recommendations were implemented [5]. Both programs delivered education via an intensive one-day course focused on foot ulcer prevention, an arrangement that all four centers were already using. This type of intervention has been shown to have an impact on knowledge, compliance with foot care advice, and diligence in attending podiatry appointments [13-15]. Each day-long TPE course included three to seven patients and was led by a multi-profession team (doctors, nurses, podiatrists, and nurse's aides) trained in TPE.

The "standard" program (G1: first arm of the study) corresponded to the usual practice at the treatment centers. Treatment centers agreed on skills to develop and educational objectives for the one-day program. The techniques and resources used to help participants attain those skills varied from one center to another. The program included three workshops aimed at developing four main skills:

- identifying situations that involve foot ulcer risk in day-today life;

- implementing self-care measures to reduce the risk of ulcer;

- detecting ulcers early and taking emergency measures when an ulcer occurs.

The "new" program (G2: second arm of the study) included modifications to two of the three standard program workshops. Caregivers at the four centers received special training for that beforehand. The training focused on a more in-depth approach to understanding the disease and on helping patients think about self-efficacy and locus of control with regard to the disease. We have developed new learning tools for the two workshops: illustrated posters, card games about risky situations, and photos of foot problems. To improve understanding of the disease, there were sessions using cognitive psychology-based learning principles [16]:

- before conveying any information, patients had to talk about their experiences, knowledge, comprehension, and reasoning;

- using learning tools (illustrated posters), patients had to explain, in their own words, connections between what 
happened (or could happen) to them and their disease, thus illustrating the rules and action principles;

- patients had an opportunity to apply what they learned in a variety of situations germane to their own lives, and to anticipate new situations.

We used Bandura's social cognitive theory to help patients develop self-efficacy [17]. At both workshops, patients had to talk about their self-efficacy regarding the target abilities: identifying high-risk situations, detecting an ulcer early, and taking emergency measures when an ulcer occurs. They had to verbalize what they were already doing, what they felt able or unable to do, and why. The educators encouraged experiencesharing, acknowledged their successes, and encouraged them to think about their difficulties. Lastly, given that it is harder to intervene directly on the locus of control [18], each patient assessed his control over the disease by indicating his position between the two endpoints of a scale, allowing a discussion of the different positions with the patients. We wrote up the exact procedure for the two modified workshops in order to harmonize, as much as possible, the practices at the different centers.

\subsection{Measures}

The patients completed four different questionnaires exploring the evaluated dimensions, at inclusion (T0) and about six months after the therapeutic education day (T1).

Since at the time there were no validated French-language instruments on the issues being explored in the study, we used those published in the English-language literature. Each questionnaire was translated from English into French and then submitted to three to four heads of the participating centers for validation of the translation and to ensure that the questions were consistent with the French recommendations. Some questions were considered useless or redundant, and others were added. We harmonized and adapted the response scales to the format typically used in France (four-point Likert scale for all questionnaires, combined with scoring systems for calculating the total score for each questionnaire).

We used the Patient Interpretation of Neuropathy (PIN) questionnaire to assess the patient's understanding of the disease $[19,20]$. Initially consisting of 39 items, it was reduced to 25 items (scored 0 to 3, minimum/maximum score: $0 / 75$ ). We omitted items related to locus of control of the disease because they were explored in another specific questionnaire (items 11 to 14 and items 22 to 24 of the original PIN). We retained only two of the three items exploring the patient's knowledge about the circumstances and time needed to develop an ulcer (items 20 and 21 of the original PIN). We removed the questions about emotional factors (items 34 to 39 of the original PIN).

We used the Foot Care Confidence Scale to explore selfefficacy $[21,22]$. We retained all twelve items (scored 1 to 4 , minimum/maximum score: $12 / 48$ ).

We adapted Form C of the Multidimensional Health Locus of Control (MHLC) scales [23] to foot ulcer problems, keeping all 18 items (minimum/maximum score for each dimension: 6/24).

We used the Nottingham Assessment of Functional Foot Care, adapted to the French context, to assess ulcer prevention behaviors [24]. We omitted 2 items (items 3 and 8) from the original questionnaire, and we added 3 items concerning foot care. There were thirty questions in all (scored 0 to 3 , minimum/maximum score: $0 / 90$ ).

We readjusted the questionnaires after being tested on five patients, who had to rate the clarity of the questions on a 4-point scale.

We collected patient social and medical characteristics at inclusion (T0). For both groups six months after TPE, we noted occurrence of a new foot ulcer, its consequences, and compliance with the podiatrist's orders and other preventive measures.

\subsection{Analysis}

We performed the analyses using Sphinx ${ }^{\circledR}$ software. We calculated each patient's scores for the various questionnaires using the scoring system for each response modality. We calculated and compared means for each group (Z-test). We used Fisher's exact test to compare percentages. The threshold for statistical significance for these tests was $p=0.05$.

\section{Results}

Of the 126 patients enrolled in the study after informed consent, seventeen (13.4\%) were lost to follow-up. We analyzed the results of 109 enrolled patients who had a 6-month follow-up; of these, $53(49 \%)$ were in the G1 (standard) group and $56(51 \%)$ in the G2 (new) group. The number of patients who completed each questionnaire was given in each case (Tabs. 1 to 4 ).

There were no significant social or medical differences between the two groups at T0 (Tab. 1), with the following exceptions: more of the G1 patients had private health insurance $(p=0.03)$ and lived alone $(p=0.02)$, and more $\mathrm{G} 2$ patients lived in a couple $(p=0.05)$ and had a relative to participate in care $(p=0.01)$.

There was no significant difference between groups G1 and $\mathrm{G} 2$ in terms of overall scores at T0 and T1 (Tab. 2). Group G2 showed a significant change in score between $\mathrm{T} 0$ and $\mathrm{T} 1$ for understanding the disease $(p=0.04)$ and patient-reported prevention behaviors $(p=0.01)$. Group G1 showed no statistically significant change in these two dimensions from T0 to T1 ( $p=0.07$ and $\mathrm{p}=0.2$, respectively) (Tab. 2).

For the sample as a whole $(n=109)$, there was a significant improvement between $\mathrm{T} 0$ and $\mathrm{T} 1$ for two questionnaires (Tab. 3): understanding of disease $(p<0.01)$ and prevention behaviors $(p<0.01)$.

Patients who reported having relative to participate in care had a significantly higher mean score on prevention behavior than patients without relative (67.85 vs. 61.26 , respectively; $\mathrm{p}<0.01)$.

There was no difference between the groups in terms of medical data and care behaviors (podiatric follow-up and wearing therapeutic footwear/ insoles) at six months, except for the type of new ulcer (same vs. different location) (Tab. 4). Twenty of the 109 patients had developed one new ulcer and two had developed two new ulcers since the TPE program ( $20.2 \%$ total), with no significant difference between groups G1 and G2. One G1 patient had undergone left toe amputation. 
Table 1. Social and medical characteristics of patients at inclusion $(n=109)$.

Tableau 1. Caractéristiques sociales et médicales des patients à l'inclusion ( $\mathrm{n}=109)$.

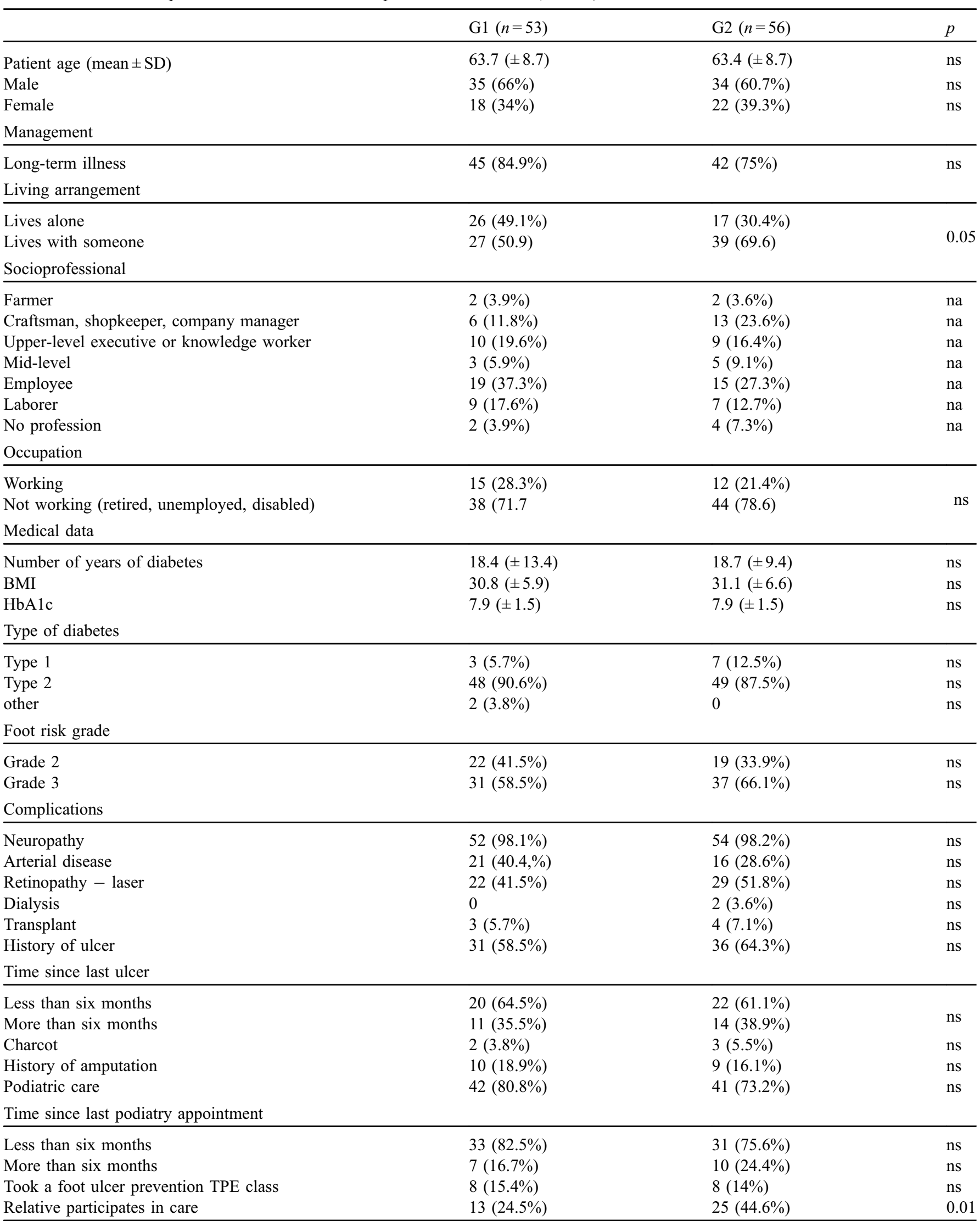

ns: test not statistically significant; na: test not applicable. Data expressed as mean $( \pm \mathrm{SD})$ or n (\%). 
Table 2. Mean scores for each questionnaire for each group (G1 and G2) at inclusion (T0) and at six months (T1).

Tableau 2. Scores moyens à chaque questionnaire et pour chaque groupe (G1 et G2) à l'inclusion (T0) et à 6 mois (T1).

\begin{tabular}{|c|c|c|c|c|c|c|c|c|}
\hline \multirow[t]{2}{*}{ Type of patient questionnaire } & \multicolumn{4}{|c|}{ G1 } & \multicolumn{4}{|c|}{$\mathrm{G} 2$} \\
\hline & $n$ & TO & $\mathrm{T} 1$ & $p$ & $n$ & TO & $\mathrm{T} 1$ & $p$ \\
\hline Understanding the disease (max. score: 75 ) & 52 & $49.5( \pm 7.8)$ & $52.8( \pm 9.9)$ & ns & 56 & $50.1( \pm 8.1)$ & $53.7( \pm 8.5)$ & 0.04 \\
\hline $\begin{array}{l}\text { Self efficacy (max. score: } 48 \text { ) } \\
\text { Locus of control }\end{array}$ & 52 & $38( \pm 4.2)$ & $39( \pm 5.1)$ & ns & 55 & $39.3( \pm 5.9)$ & $40.7( \pm 4.9)$ & ns \\
\hline Internal (max. score: 24$)$ & & $18.3( \pm 3)$ & $18.5( \pm 3.5)$ & ns & & $17.5( \pm 3.5)$ & $18.1( \pm 3.7)$ & ns \\
\hline Chance (max. score: 24$)$ & 47 & $12( \pm 3.5)$ & $10.8( \pm 3.5)$ & ns & 54 & $12.2( \pm 3.1)$ & $11.5( \pm 3.6)$ & ns \\
\hline Other (max. score: 24$)$ & & $19.1( \pm 2.4)$ & $19.6( \pm 2.7)$ & ns & & $18.9( \pm 2.6)$ & $19.9( \pm 2.8)$ & ns \\
\hline Prevention behaviors (max. score: 90 ) & 52 & $61( \pm 8.2)$ & $63.3( \pm 9.6)$ & $\mathrm{ns}$ & 52 & $60.4( \pm 9)$ & $65.3( \pm 8.2)$ & 0.01 \\
\hline
\end{tabular}

Data are expressed as mean $( \pm \mathrm{SD})$.

There were no significant social differences (at T0) between the patients that developed a new ulcer and those that did not. The former were, however, at high risk for ulcer: $95.5 \%$ $(21 / 22)$ had a previous history of ulcers as compared to $52.4 \%$ of the group that did not develop a new ulcer $(p<0.01)$, and $36.4 \%(8 / 22)$ had a history of amputation as compared to $10.7 \%$ of the group without a new ulcer $(p<0.01)$.

G1 patients were more likely to have developed an ulcer in a new location $(10 / 11 v s .5 / 11)(p=0.03)$, while G2 patients were more likely to have an ulcer recurrence in the same location $(6 / 11$ vs. $1 / 11)(p=0.03)$.

The ulcers occurred from four months (G2) to six months (G1) after the TPE program, with G1 having a longer time to onset than G2 (167.8 \pm 97 and $119.9 \pm 61.1$ days, respectively).

\section{Conclusion}

A comparison of the two groups of patients, G1 and G2, showed no statistically significant differences at $\mathrm{T} 1$ in the scores for the four dimensions evaluated. The first explanation may be limited power due to the small sample size of each group, since there were significant changes from $\mathrm{T} 0$ to $\mathrm{T} 1$ for the sample as a whole $(n=109)$. The second explanation may relate to the intervention modalities. Unlike a classic comparative study (comparing a group receiving education to a group receiving the usual care, or comparing a short to an intensive intervention), the duration of exposure to TPE was exactly the same for G1 and G2, as were the target objectives and skills. This makes it harder to demonstrate a difference in effect. A third hypothesis is a possible contamination bias, because the teams became aware of the patients' difficulties when presented with the results from the first study, which showed that patients with ulcer recurrence had problems understanding the disease [7]. This may have resulted in an effort to improve TPE during the study, starting with the inclusion of the first patients in the first arm of the study. Because the education sessions were not observed, this hypothesis cannot be verified.

Our results seem to show that the "new" program had a positive effect on patients' understanding of the disease and application of prevention behaviors (significant changes found only in group G2). However, like all complex interventions conducted in everyday practice, it is impossible to determine exactly what in the intervention itself was responsible for the results observed (how the sessions were run, the types of speakers, the level of patient participation, the effect of novelty, etc.) [25]. Those effects may be due to the better social support that group G2 patients receive (being in a couple and having relative to participate in care), of which the literature has shown the benefits [26-28].

Analyzing the sample as a whole $(n=109)$, the study shows that therapeutic patient education significantly improves patients' understanding of the disease and foot ulcer prevention behaviors between $\mathrm{T} 0$ and $\mathrm{T} 1$, both programs combined $(p<0.01)$. This confirms the results in the literature showing the benefit of TPE for knowledge acquisition and application of prevention behaviors [29]. Prevention behaviors were even better when a relative helped with care $(p<0.01)$, highlighting the importance of social support in managing the disease [28]. It is possible to explain the lack of significant change in self-efficacy between $\mathrm{T} 0$ and $\mathrm{T} 1$ for the sample as a whole by the particularly high score at T0 (some patients already scored more than $80 \%$ of the maximum at T0). That may seem surprising, given that few of the patients (approximately 15\%) reported participating in a specific ulcer prevention education program (that is, multiple sessions) at the time of inclusion in the study. It is likely, however, that the patients had received information during more general TPE programs on diabetes or in the course of their medical care for diabetes (mean disease duration was 18 years), giving them self-efficacy in preventing foot ulcers. TPE appears to have reinforced self-efficacy, a high degree of which is necessary and correlated in the literature to implementation of health behaviors [10,30]. Regarding the locus of control, education seems to have slightly improved patients' perceived control over their foot problems. Before the education program, patients attributed their problem to external and internal factors (others and themselves, respectively) in roughly the same proportion. After the education program, chance was felt to play a smaller role in control of the disease, and the two other dimensions a larger role. The lack of any real change in the locus of control may be explained by the fact that it is well known to be relatively stable [18], though it can evolve over the long term [31]. Hence, longer-term follow-up is warranted to more accurately assess changes in that dimension.

Sixty-one percent of the study patients had a history of foot ulcers, two thirds of them less than six months prior to inclusion. The ulcers in these high-risk patients have 
Table 3. Mean scores on patient questionnaires for the sample as a whole at $\mathrm{T} 0$ and $\mathrm{T} 1$.

Tableau 3. Scores moyens à chaque questionnaire pour l'échantillon total à T0 et T1.

\begin{tabular}{lclll}
\hline \multicolumn{1}{c}{ Questionnaire } & $n$ & \multicolumn{1}{c}{ T0 } & \multicolumn{1}{c}{$p$} \\
\hline Understanding of the disease (max. score: 75$)$ & 108 & $49.8( \pm 7.9)$ & $53.2( \pm 9.3)$ & 0.01 \\
Self efficacy (max. score: 48) & 107 & $39.1( \pm 5.1)$ & $39.9( \pm 5)$ & $\mathrm{ns}$ \\
Locus of control & 101 & & & $\mathrm{~ns}$ \\
Internal (max. score: 24) & & $17.9( \pm 3.3)$ & $18.3( \pm 3.6)$ & $\mathrm{ns}$ \\
Chance (max. score: 24) & & $12.1( \pm 3.3)$ & $11.1( \pm 3.7)$ & $\mathrm{ns}$ \\
Other (max. score: 24) & 104 & $60.7( \pm 8.6)$ & $64.1( \pm 9.1)$ & $<0.01$ \\
Prevention behaviors (max. score: 90) & &
\end{tabular}

Data are expressed as mean $( \pm \mathrm{SD})$.

Table 4. Medical data and care behaviors at six months.

Tableau 4. Données médicales et autres comportements de prévention à 6 mois.

\begin{tabular}{|c|c|c|c|}
\hline & G1 $(n=53)$ & G2 $(n=56)$ & $p$ \\
\hline New ulcer & $11(22 \%)$ & $11(19.6 \%)$ & ns \\
\hline \multicolumn{4}{|l|}{ Type of ulcer } \\
\hline Same location as previous ulcer & $1(9.1 \%)$ & $6(54.5 \%)$ & 0.03 \\
\hline Different location than previous ulcer & $10(90.9 \%)$ & $5(45.5 \%)$ & 0.03 \\
\hline Mean number of GP visits & $0.6( \pm 1.2)$ & $0.6( \pm 1)$ & ns \\
\hline Mean number of hospital specialist visits & $2.6( \pm 3.5)$ & $3( \pm 3.7)$ & $\mathrm{ns}$ \\
\hline Mean number of private medical specialist visits & $0.1( \pm 0.3)$ & $0.3( \pm 0.5)$ & ns \\
\hline Mean number of private $\mathrm{RN}$ visits & $51.3( \pm 76.2)$ & $40.9( \pm 61.2)$ & ns \\
\hline Mean number of hospital RN visits & $4( \pm 5.9)$ & $3.1( \pm 4.1)$ & ns \\
\hline Hospitalization & $2(18.2 \%)$ & $2(18.2 \%)$ & ns \\
\hline \multicolumn{4}{|l|}{ Place of hospitalization } \\
\hline Short stay & $2(100 \%)$ & $1(100 \%)$ & ns \\
\hline Mean number of days on work leave & $25( \pm 25.5)$ & $30( \pm 0)$ & ns \\
\hline Amputation & $1(9.1 \%)$ & 0 & ns \\
\hline Left toe & $1(100 \%)$ & 0 & ns \\
\hline \multicolumn{4}{|l|}{ Therapeutic footwear purchased } \\
\hline Yes & $21(77.8 \%)$ & $30(83.3 \%)$ & ns \\
\hline No & $5(22.2 \%)$ & $6(16.7 \%)$ & \\
\hline \multicolumn{4}{|l|}{ Shoes worn } \\
\hline Rarely/never & $2(9 \%)$ & $2(6.7 \%)$ & ns \\
\hline Often/always & $20(91 \%)$ & $28(93.3 \%)$ & \\
\hline \multicolumn{4}{|l|}{ Insoles purchased } \\
\hline Yes & $27(90 \%)$ & $34(89.5 \%)$ & ns \\
\hline No & $3(10 \%)$ & $4(10.5 \%)$ & \\
\hline \multicolumn{4}{|l|}{ Insoles used } \\
\hline Rarely/never & 0 & $3(9.4 \%)$ & ns \\
\hline Often/always & $27(100 \%)$ & $29(90.6 \%)$ & \\
\hline \multicolumn{4}{|l|}{ Insoles replaced } \\
\hline Rarely/never & $9(34.6 \%)$ & $19(30 \%)$ & $\mathrm{ns}$ \\
\hline Often/always & $17(65.4 \%)$ & $21(70 \%)$ & \\
\hline Mean number of podiatry visits since TPE program & $2.6( \pm 2.4)$ & $2.1( \pm 1.5)$ & $\mathrm{ns}$ \\
\hline
\end{tabular}

Data are expressed as mean $( \pm \mathrm{SD})$.

multiple causes, both behavioral and related to complex biomechanical factors. For example, rubbing or excessive pressure from a significant foot deformity can lead to ulcer formation, often making ulcers unavoidable in feet with reduced sensitivity ( $98 \%$ neuropathy in our study). The effectiveness and full-time wear of preventive devices such as orthopedic insoles and/or shoes should be considered along with the TPE results when measuring ulcer recurrence. By six months, eleven patients in each group (about 11\%) had developed an ulcer (or two), with no significant difference between the groups, although our sample size was only 109 patients and a sample size of 430 to 870 per arm would be needed to show a $50 \%$ difference in ulcers between the two arms of a TPE efficacy study [29]. 
This study has some limitations. The impossibility of implementing a randomized controlled study in current practice, as well as the inherent bias of this type of study, led us to opt for a feasibility study allowing us to highlight the first pedagogical effects of an improved therapeutic education program, while reducing the contamination bias linked to educators' practices. In addition, this study included a small sample size, a lack of clinical monitoring or monitoring of the actual educational modalities, and an insufficient follow-up period. Though the questionnaires used in the study were validated, they had to be translated into French without psychometric validation. Hence, there may have been certain response biases, including misconstruing the questions on the self-administered questionnaires, stereotype bias, and social desirability bias.

In conclusion, this study confirms the effectiveness of therapeutic patient education in improving knowledge, understanding of the disease, and prevention behaviors in patients with diabetes at risk for chronic foot ulcers. A therapeutic patient education that emphasizes development of the psycho-cognitive dimensions appears to improve patients' understanding of the disease and reinforce self-efficacy. Therapeutic patient education is one component of the necessarily multidisciplinary management for preventing ulcer development, which is multifactorial.

Acknowledgments. This study was funded by the URGO Foundation, which we thank for both funded and organizational support. We would also like to thank the healthcare professionals and the patients at each center for their participation in the education program.

Conflicts of interest. The authors declare that they have no conflicts of interest in relation to this article.

\section{References}

1. Ha Van G, Hartemann-Heurtier A, Lejeune M. Le pied diabétique. In: Traité de diabétologie. Paris: Flammarion médecine-sciences; 2009, pp. 789-790.

2. Armstrong DG, Boulton AJM, Bus SA. Diabetic foot ulcers and their recurrence. N Engl J Med 2017; 376(24):2367-2375.

3. Apelqvist J, Larsson J, Agardh CD. Long-term prognosis for diabetic patients with foot ulcers. J Intern Med 1993; 233 (6):485-491.

4. Dorresteijn JAN, Kriegsman DMW, Assendelft WJ, Valk GD. Patient education for preventing diabetic foot ulceration. Cochrane Database Syst Rev 2012; (10):CD001488.

5. International Working Group on the Diabetic Foot (IWGDF). The 2015 IWGDF Guidance documents on prevention and management of foot problems in diabetes: Development of an evidence-based global consensus. IWGDF Editorial Board; 2015, available from: http://www.iwgdf.org/files/2015/website_ development.pdf.

6. Bus SA, van Netten JJ, Lavery LA, Monteiro-Soares M, Rasmussen A, Jubiz Y, et al. IWGDF guidance on the prevention of foot ulcers in at-risk patients with diabetes. Diabetes Metab Res Rev 2016; 32:16-24.

7. Marchand C, Ciangura C, Griffe V, Pinosa C, HaVan G, Hartemann A, et al. Barriers to preventive and curative foot care behaviors in person with diabetes. Suggestions for therapeutic patient education. Educ Ther Patient/Ther Patient Educ 2012; 4 (2):S135-S142.

8. Peyrot M, Rubin RR. Structure and correlates of diabetesspecific locus of control. Diab Care 1994; 17(9):994-1001.

9. Reynaert C, Janne P, Donckier J, Buysschaert M, Zdanowicz N, Lejeune $\mathrm{D}$, et al. Locus of control and metabolic control. Diabetes Metab 1995; 21(3):180-187.

10. Johnston-Brooks CH, Lewis MA, Garg S. Self-efficacy impacts self-care and HbA1c in young adults with type I diabetes. Psychosom Med 2002; 64(1):43-51.

11. Williams GC, McGregor HA, King D, Nelson CC, Glasgow RE. Variation in self-efficacy, glycemic control, and patient satisfaction: Relationship to autonomy support from physicians. Patient Educ Couns 2005; 57(1):39-45.

12. Sarkar U, Fisher L, Schillinger D. Is self-efficacy associated with diabetes self-management across race/ethnicity and health literacy? Diab Care 2006; 4;29(4): 823-829.

13. Barth R, Campbell LV, Allen S, Jupp JJ, Chisholm DJ. Intensive education improves knowledge, compliance, and foot problems in type 2 diabetes. Diabet Med 1991; 8(2):111-117.

14. Fan L, Sidani S, Cooper-Brathwaite A, Metcalfe K. Improving foot self-care knowledge, self-efficacy, and behaviors in patients with type 2 diabetes at low risk for foot ulceration: A pilot study. Clin Nurs Res 2013; 23(6):627-643.

15. Ahmad Sharoni SK, Minhat HS, Mohd Zulkefli NA, Baharom A. Health education programmes to improve foot self-care practices and foot problems among older people with diabetes: A systematic review. Int J Older People Nurs 2016; 11(3):214-239.

16. Ausubel DP. Novak DJ, Hanesian H. Educational psychology: A cognitive view. New York: Holt, Rinehart and Winston; 1978.

17. Bandura A. (Ed.) Self-efficacy in changing societies. New York: Cambridge University Press; 1995.

18. Rotter JB. Generalized expectancies for internal versus external control of reinforcement. Psychol Monogr 1966; 80(1):1-28.

19. Vileikyte L, Gonzalez JS, Leventhal H, Peyrot MF, Rubin RR, Garrow A, et al. Patient Interpretation of Neuropathy (PIN) Questionnaire: An instrument for assessment of cognitive and emotional factors associated with foot self-care. Diab Care 2006; 29(12):2617-2624.

20. Perrin BM, Swerissen H, Payne CB, Skinner TC. Cognitive representations of peripheral neuropathy and self-reported footcare behaviour of people at high risk of diabetes-related foot complications. Diabet Med 2014; 31(1):102-106.

21. Sloan HL. Developing and testing of the Foot Care Confidence Scale. J Nurs Meas 2002; 10(3):207-218.

22. Perrin BM, Swerissen H, Payne C. The association between footcare self efficacy beliefs and actual foot-care behaviour in people with peripheral neuropathy: A cross-sectional study. J Foot Ankle Res 2009; 2:3.

23. Wallston KA. The validity of the multidimensional health locus of control scales. J Health Psychol 2005; 10(5):623-631.

24. Lincoln NB, Jeffcoat WJ, Ince $P$, Smith $M$, Radford KA. Validation of a new measure of protective footcare behaviour: The Nottingham Assessment of Funcional Footcare (NAFF). Pract Diabetes Int 2007; 24:207-211.

25. Moore GF, Audrey S, Barker M, Bond L, Bonell C, Hardeman $\mathrm{W}$, et al. Process evaluation of complex interventions: Medical Research Council guidance. BMJ 2015; 350:h1258.

26. Shrivastava SR, Shrivastava PS, Ramasamy J. Role of self-care in management of diabetes mellitus. J Diabetes Metab Disord 2013; 12:14. 
27. Ahmed Z, Yeasmeen F. Active family participation in diabetes self-care: A commentary. Diabetes Manag 2016; 6(5):104-107.

28. Song Y, Nam S, Park S, Shin I, Ku BJ. The impact of social support on self-care of patients with diabetes: What is the effect of diabetes type? Systematic review and meta-analysis. Diabetes Educ 2017; 43(4).

29. Dorresteijn JA, Kriegsman DM, Assendelft WJ, Valk GD. Patient education for preventing diabetic foot ulceration. Cochrane Database Syst Rev 2014; (12):CD001488.
30. Wu S-FV, Lee M-C, Liang S-Y, Lu Y-Y, Wang T-J, Tung H-H. Effectiveness of a self-efficacy program for persons with diabetes: A randomized controlled trial. Nurs Health Sci 2011; 13(3):335-343.

31. Howorka K, Pumprla J, Wagner-Nosiska D, Grillmayr H, Schlusche C, Schabmann A. Empowering diabetes out-patients with structured education: Short-term and long-term effects of functional insulin treatment on perceived control over diabetes. J Psychosom Res 2000; 48(1):37-44.

Cite this article as: Marchand C, Margat A, Deccache C, Ha Van G, M'Bemba J, Schuldiner S, Martini J, Parer C, Gagnayre R, Lombrail P, d'Ivernois JF, Hartemann A. Evaluation of two therapeutic patient education programs for prevention of diabetic foot ulcers. Educ Ther Patient/Ther Patient Educ 2018;10:10201. 